\title{
The phonological loop in medicated patients with Parkinson's disease: presence of phonological similarity and word length effects
}

\author{
Olivier Moreaud, Nathalie Fournet, Jean-Luc Roulin, Bernadette Naegele, Jacques Pellat
}

\begin{abstract}
Objective-To test the verbal subsystem of Baddeley's working memory model (the phonological loop) in patients with Parkinson's disease.

Methods-Fifteen patients with idiopathic Parkinson's disease and 15 controls were tested with a span paradigm to assess the effects reflecting the functioning of the phonological loop: the phonological similarity effect (in verbal and visual presentation), and the word length effect (in visual presentation).

Results and conclusions-The patients did not show any dysfunction of the phonological loop, reflected by the presence of phonological similarity and word length effects, but had lower spans than controls. The implications of these results for the working memory model are discussed.
\end{abstract}

$(\mathfrak{F}$ Neurol Neurosurg Psychiatry 1997;62:609-611)

Keywords: working memory; phonological loop; Parkinson's disease; attention; frontal lobe

A deficit of the attentional component of the working memory model, the central executive ${ }^{1}$ is suggested to explain the impairment of patients with Parkinson's disease in tests requiring intact frontal lobe function..$^{23}$ In a previous study, ${ }^{4}$ we challenged the fact that the central executive is inevitably impaired in Parkinson's disease: we tested 15 medicated patients with Parkinson's disease with a dual task minimising motor demands, combining visual, verbal, or spatial spans with articulatory suppression. The attentional cost of articulatory suppression was progressively increased. We hypothesised that a dysfunction of the central executive would result in a more pronounced effect (lower spans) of higher cost interference in Parkinson's disease than in controls. Yet, although patients with Parkinson's disease had lower spans than controls, whatever the modality and whatever the interference, we were not able to find direct evidence for a dysfunction of the central executive. We were then left with results difficult to interpret with Baddeley's model. The fact that the spans of patients with Parkinson's disease were systematically lower than those of controls was particularly puzzling. A deficit of the subsystems could not be ruled out to explain part of our results.

In Baddeley's model, ${ }^{15}$ the phonological loop is responsible for the short term retention of verbal information. It is assumed to be composed of two components: a phonological store and an articulatory control process. The phonological store holds verbal information, whether presented verbally or visually, in the form of a phonological code. The holding of the verbal material in this form is probably the reason why similar items, which have confusable codes, lead to impaired performance-an effect known as the phonological similarity effect (PSE). As the retention of information in the phonological loop is limited to a few seconds, the verbal material is refreshed by an articulatory process, based on inner speech. A consequence of this process is that the spoken duration of words is crucial to the determination of span: longer words lead to lower spans-an effect known as the word length effect (WLE). Both PSE and WLE reflect the integrity of the phonological loop, and are used as indicators of its functioning. We present here a study designed to assess the phonological loop in Parkinson's disease. The aim was twofold: to our knowledge, the classic effects reflecting the functioning of the phonological loop (phonological similarity effect and word length effect) have never been tested in Parkinson's disease; moreover, the results of such a study would allow us to go further in the interpretation of our previous study.

\section{Methods}

SUBJECTS

Fifteen patients with idiopathic Parkinson's disease and 15 volunteer controls, matched for age, educational level, and verbal $\mathrm{IQ}^{6}{ }^{6}$ were tested. These patients were the same as those tested in our previous study. Patients with clinical evidence of dementia, history of stroke, head injury, meningitis, neurosurgical intervention, and alcoholism or drug consumption, were excluded. All patients with Parkinson's disease were diagnosed by a neurologist. There were nine men and six women. The mean duration of the disease was 8.0 (SD $4 \cdot 8)$ years. The severity of the disease was rated with the score in the motor part of the unified Parkinson's disease rating scale (mean 21.8 (SD 11.7)), and the Hoehn and Yahr scale. ${ }^{8}$ Two patients were classified at Hoehn and Yahr stage I, 12 at stage II, and one at stage III. At the time of testing, all patients were taking levodopa with a decarboxylase inhibitor; 11 patients were taking a dopamine agonist (bromocryptine or piribedil), and one patient was taking selegiline. The mean ages of 
patients and controls were $66.06(\mathrm{SD} 8 \cdot 2)$ and 66.6 (SD 11.5) respectively, the mean numbers of years of education $9 \cdot 73$ (SD $4 \cdot 1$ ) and $10 \cdot 27$ (SD 3.75), and the mean verbal $\mathrm{IQ}^{6}$ $111 \cdot 13$ (SD 13.4) and 114.47 (SD 12.4). All patients gave informed consent.

\section{PROCEDURE}

The method of word span was used. Words were presented both visually and verbally. For the visual presentation, subjects were seated in front of the screen of a microcomputer (Amstrad PC 1512; size of the screen $255 \mathrm{~mm}$ $\times 205 \mathrm{~mm}$ ). The distance from eye to screen was roughly $60 \mathrm{~cm}$. Words were presented sequentially on the screen at a rate of one word every $700 \mathrm{~ms}$. Each word was seen for $800 \mathrm{~ms}$. Subjects were instructed to read them silently and to keep them in their memory. After a four second delay, a question mark appeared on the screen. This indicated to the subjects that they should record as many words as they could. For the verbal presentation, the words were read by the examiner when appearing on the screen, which was not visible to the subjects; when the question mark appeared, the examiner told the subjects to record the words. The number of words was progressively increased and spans were assessed using the methodology of the WAIS. ${ }^{9}$ Three successive trials were made. The span in each trial was the maximal number of items recalled, minus 0.5 if the subject recalled this maximal number after having failed once. The final span was the average of the three spans obtained. A comparison of mean spans for two syllable phonologically similar and dissimilar words was made to assess PSE. Words were chosen randomly from two lists of 18 French words: one list of phonologically dissimilar words-for example, volcan-prison (English, volcano-prison), and one list of phonologically similar words-for example, bateau-chateau (English, boat-castle). The mean frequency of the lists was equal. WLE was tested by comparing mean spans for one, two, or three syllable dissimilar French words, randomly chosen from three lists (the list of two syllabled words was the same as previously used for the PSE). The lists had equal mean frequency. WLE was

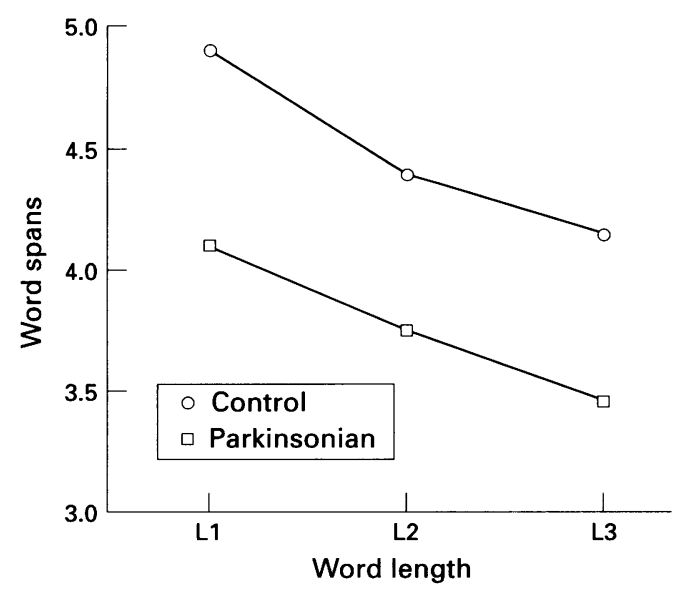

Spans for one, two, or three syllable words in parkinsonian patients and in controls. assessed only on visual presentation of words. The experiment was divided into two sessions, one for WLE and another for PSE. Half of the subjects of each group were tested for WLE first, and then for PSE. The order was reversed for the other half of each group. For WLE, the spans for one syllable words were always assessed first, then for two syllable words, and finally for three syllable words. For PSE, spans for non-similar words presented verbally were assessed first, then spans for similar words presented visually, and finally spans for similar words presented verbally. Spans for non-similar words presented visually were assessed during the session for WLE.

\section{Results}

Analysis of mean spans in the tasks was carried out by analysis of variance (ANOVA).

WORD LENGTH EFFECT (FIGURE)

There was a significant effect of group ( $F$ $(1-28)=7 \cdot 26 ; \mathrm{P}<0.05)$ and of word length $(F(2-56)=33.97 ; \mathrm{P}<0.01)$. No significant group $\times$ length interaction was found $(F$ $(2-56)=0.87$; NS). Thus parkinsonian patients had lower spans than control subjects, but WLE was similar in both groups.

PHONOLOGICAL SIMILARITY EFFECT

On verbal presentation, the mean spans for similar words of parkinsonian patients and control subjects were respectively $3 \cdot 1$ (SD $0 \cdot 9$ ) and $3.6(\mathrm{SD} 0.6)$, and for dissimilar words 4.3 (SD 0.9) and 4.7 (SD 0.9). On visual presentation, they were, for similar words respectively $3 \cdot 1$ (SD 0.7 ) and 3.6 (SD $0 \cdot 7$ ), and for dissimilar words 3.7 (SD 0.9 ) and 4.4 (SD $1 \cdot 0)$. There was a significant effect of group $(F$ $(1-28)=7.65 ; \quad \mathrm{P}<0.01)$, of similarity $(F$ $(1-28)=83.1 ; P<0.01)$, and of presentation $(F(1-28)=19.24 ; \mathrm{P}<0.01)$. There was neither group $\times$ similarity interaction $(F(1-28)$ $=0.01$; NS), nor group $\times$ presentation interaction $(F(1-28)=0.01 ; \mathrm{NS})$. This suggests the presence of a PSE in both groups, even if parkinsonian patients had lower spans than control subjects. Significant presentation $\times$ similarity $(F(1-28)=15 \cdot 17 ; \mathrm{P}<0.01)$ and group $\times$ similarity $\times$ presentation $(F(1-28)=$ $7 \cdot 5 ; \mathrm{P}<0.05)$ interactions were found.

\section{Discussion}

The results clearly show that medicated patients with Parkinson's disease present the classic WLE and PSE known to reflect the functioning of the phonological loop. Yet the mean spans of the group of parkinsonian patients were systematically lower than those of controls. These findings were similar to another study, in which we tested the same patients. ${ }^{4}$ In this study, we suggested that the lower spans in parkinsonian patients could not be explained by a deficit of the central executive component of Baddeley's model, even if such a deficit is suggested by others. ${ }^{310}$ The results of the present experiment show that a deficit in the functioning of the phonological 
loop is not a reasonable explanation. Indeed, even if the lower verbal spans of parkinsonian patients in the context of a presence of WLE and ESP could be the result of a less efficient phonological loop in the patients, this does not explain why our previous study found lower spans even with non-verbal material. ${ }^{4} \mathrm{We}$ could also propose that the deficit is the consequence of a greater interference for patients with Parkinson's disease during the recall of the material: in the same time that the words are uttered, part of them must still be maintained by rehearsal; this rehearsal is perhaps prevented by utterance in parkinsonian patients more than in controls. However, once again, as in our previous study, ${ }^{4}$ the spans of patients with Parkinson's disease were decreased compared with controls, even when the material was visual or spatial in nature, and even in the absence of structural interference. Moreover, it is also known that the functioning of the phonological loop is not dependent on outer speech, and that dysarthric patients show normal spans and manifest the presence of WLE and PSE. ${ }^{5}$ If the results for patients with Parkinson's disease do not reflect a dysfunction either of the phonological loop, or of the central executive, ${ }^{4}$ then how are they explained? The role of the delay during the rehearsal of the material may be suspected, but is not easily interpretable in the frame of Baddeley's model. We plan to evaluate it in a further study. Another hypothesis assumes that verbal span tasks are simply more difficult for parkinsonian patients than for controls, or reflect perceptual, motivational, or general attentional difficulties that might impair the performance by preventing normal access of the material during its presentation. If that were the case, in the absence of a deficit of the central executive, ${ }^{4}$ a respecification of Baddeley's model would be needed. However, such a respecification seems premature, because some studies, using a different methodology, suggest a deficit of the allocation of attentional resources by the central executive. ${ }^{310}$

This study has received support from Le Centre National de la Recherche (GDR 978).

1 Baddeley AD. Working memory. London: Oxford University Press, 1986.

2 Brown RG, Marsden CD. Dual task performance and processing resources in normal subjects and patients with Parkinson's disease. Brain 1991;114:215-31.

3 Dalrymple-Alford JC, Kalders AS, Jones RD, Watson RW. A central executive deficit in patients with Parkinson's A central executive deficit in patients with Parkinson's

4 Fournet N, Moreaud O, Roulin JL, Naegele B, Pellat J. Wournet N, Moreaud O, Roulin JL, Naegele B, Pellat J. Working memory in medicated Parkinson's disease Neurosurg Psychiatry, 1996;60:313-7.

5 Baddeley AD. Human memory: theory and practice. New York: Allyn and Bacon, 1990.

6 Binois R, Pichot P. Test de vocabulaire. Paris: Centre de Psychologie Appliquée, 1947.

7 Fahn S, Elton RL, and members of the UPDRS development committee. Unified Parkinson's disease rating scale. In: Fahn S, Marsden CD, Caine D, Goldstein M, eds. Recent development in Parkinson's disease. Florham Park, NJ: McMillan Health Care Information, USA, 1987:153-63.

8 Hoehn MM, Yahr MD. Parkinsonism: onset, progression and mortality. Neurology 1967;17:427-42.

9 Wechsler D. The Wechsler adult intelligence scale (manual). New York: Psychological Corporation, 1955.

10 Robertson C, Hazlewood R, Rawson MD. The effects of Parkinson's disease on the capacity to generate information randomly. Neuropsychologia 1996;34:1069-78. 